\title{
LA FIGURA DE MIGUEL DELIBES EN LA CULTURA EUROPEA FINISECULAR: PROYECCIÓN Y ANÁLISIS
}

\author{
Cecilia Vega Martín \\ Universidad de Málaga. España.
}

A estas alturas del siglo, resulta indiscutible que Miguel Delibes ocupa uno de los puestos más relevantes en nuestro panorama literario. Como es sabido, desde que en 1947 el premio Nadal lo diera a conocer como novelista hasta que hace dos años recibiera el premio Cervantes, el autor vallisoletano ha sido condecorado con los principales galardones de la Literatura Española.

Delibes, cuyas obras están siendo traducidas a los principales idiomas del mundo, ha pronunciado innumerables conferencias y ha impartido cursos en diversas Universidades europeas y americanas, ha sido investido Doctor Honoris Causa por la Universidad de El Sarre (Alemania) en mayo de 1990, y nombrado Caballero de la Orden Francesa de las Artes y las Letras de la República Francesa (1985). Su producción está siendo continuamente analizada en un sinfín de memorias de licenciatura y tesis doctorales en Alemania, Francia, Suecia, Inglaterra, Bélgica... Todo ello demuestra que su prestigio rebasa con mucho los límites de nuestras fronteras.

Pese a su obstinada fidelidad al entorno castellano, Delibes no ha renunciado al conocimiento de nuevas tierras. Sus viajes surgieron generalmente con motivo de invitaciones cursadas al novelista por universidades y entidades culturales extranjeras para pronunciar conferencias o asistir a congresos literarios. Todos ellos hallan eco en sus libros, ya sea en los de ficción o en las crónicas viajeras: de su viaje en 1955 a América del Sur (propiciado 
por una invitación del Círculo de Periodistas de Santiago de Chile) nacen dos libros: Un novelista descubre América (refundido después en Por esos mundos) y Diario de un emigrante. En Europa: parada y fonda ofrece el escritor impresiones de su viaje a Italia (Milán, Turín, Roma) y Portugal (Coimbra y Lisboa) en 1956; de su estancia en París en 1958, invitado por el Congreso por la Libertad de la Cultura, y de su visita a varias universidades alemanas en 1959.

En 1964 es invitado por la Universidad de Maryland a pasar un semestre como profesor visitante. Viaja por un gran número de estados americanos pronunciando conferencias. Fruto de esa experiencia es su libro USA y yo.

En 1968, meses antes de la intervención soviética del 21 de agosto, Delibes visita Checoslovaquia. En su extraordinaria crónica (La primavera de Praga), el escritor sólo pretende "dejar constancia de una tentativa: [...] una pacífica evolución política hacia un socialismo humanista y democrático, que los propios checos han denominado Primavera de Praga" '. Consecuencia de su viaje a Suecia en 1980 y a los Países Bajos en 1981 es el libro Dos viajes en automóvil.

Finalmente, Delibes recoge experiencias de su viaje en 1990 a El Sarre -a raíz de su nombramiento como Doctor Honoris Causa por esa Universidad- en su artículo "Un hombre de aire libre", que incluye el discurso pronunciado en el acto de investidura ${ }^{2}$.

En definitiva, Delibes ha recorrido el mundo, pero ha regresado siempre a su paisaje original, a su entorno castellano. Es más, cada viaje le ha servido para descubrir Castilla: "Porque, en efecto, Castilla, la Castilla de mis libros — dice el propio autor-, sólo he acertado a verla tal como es, después de recorrer Europa y todo el continente americano. Y aún añadiría más: cada salida mía al extranjero me ayuda a percibir un nuevo matiz de Castilla, matiz que hasta ese momento me había pasado inadvertido" ${ }^{3}$.

Aunque hoy está considerado la más pura voz de Castilla, se cumple en él la aparente paradoja del escritor que, anclado en su realidad más próxima, adquiere mayor universalidad al profundizar en su propia circunstancia ${ }^{4}$.

La narrativa de Delibes está accionada por un propósito fundamentalmente ético. El propio autor ha reconocido:

En la medida en que yo pueda cooperar a mejorar un mundo que no me gusta lo hago. Entonces resulta que el libro lleva un intento moralizador siempre. Yo comprendo que los libros que han de quedar van a quedar por sus virtudes estéticas, pero yo no puedo olvidarme de la finalidad ética. A la hora de escribir un libro tengo dos objetivos: una preocupación estérica y otra moral. ${ }^{5}$ 
De ahí que la concepción delibeana de la novela se base en el rechazo de la innovación por la innovación, y en la defensa del contenido narrativo como eje fundamental del relato. En sus propias palabras: "me parece encomiable toda reivindicación de la forma novelesca siempre que tengamos en cuenta que esa forma, sea cual sea, hay que llenarla necesariamente con algo" 6 .

Delibes ha mantenido esta postura a lo largo de toda su trayectoria narrativa, incluso cuando empezó a perder valor la exigencia de una postura crítica para la creación literaria; cuando la novela, bajo la presión del experimentalismo lingüístico, abandonó los caminos del realismo social para reivindicar la búsqueda de nuevas formas expresivas.

De esta manera, Miguel Delibes se ha convertido en portavoz de muchas de las propuestas éticas que rechazan el sentido imprimido a la civilización contemporánea. A través de la ideología de sus protagonistas, o del planteamiento moral desde el que sus caracteres se configuran, el autor expone un mensaje de transformación en el modo de ser y de pensar de la sociedad actual. Lucha contra "el adocenamiento ético-colectivo que coopera [...] a la continuidad de un orden y seguridad preestablecidos, que existen [...] sólo aparentemente" ?.

Se ha escrito mucho acerca de la oposición delibeana al sentido moderno del progreso, un enfrentamiento que el autor refleja no sólo a lo largo de su producción literaria sino también a través de ensayos, conferencias y artículos periodísticos, y analiza pormenorizadamente en su discurso de ingreso en la Real Academia Española, titulado inicialmente El sentido del progreso desde mi obra y editado posteriormente como El mundo en la agonía. En él, Delibes hace un "llamamiento a la cordura y a la necesidad de dar al progreso un enfoque que conceda prioridad, ante todo, a la vida, a la solidaridad entre los hombres y a la concordia del hombre con la Naturaleza" 8 .

Desde sus primeras obras, el autor de $E l$ camino ha demostrado una clara "obsesión antiprogreso", una denuncia contra la deshumanización progresiva de la sociedad y la agresión a la naturaleza como resultados de una misma actitud: la entronización de las cosas. De ahí que para Delibes el verdadero progreso no estribe en el desarrollo ilimitado y competitivo, ni en fabricar cada día más cosas, ni en inventar necesidades al hombre, ni en destruir la Naturaleza, sino en establecer las relaciones Hombre-Naturaleza en un plano de concordia. Delibes, sin embargo, no duda en expresar su pesimismo en este sentido. En su opinión

contamos con suficientes signos para advertir que el final de la historia está más próximo cada día. No nos engafiemos. El hecho de que un día desapatezcan del mundo los olmos y que otro día desaparezcan los cangrejos y otro 
la perdiz silvestre... me parece lo suficientemente expresivo como para ratificar que el deterioro de la cadena biológica alcanzará, a no tardar, al hombre mismo. [...] Esto es un mal presagio y, por otra parte, una prueba de la incapacidad de las sociedades para abordar en profundidad sus problemas?

Para Delibes, el único dato positivo que, en este sentido, cabe extraer de la civilización moderna es la extensión de la conciencia moral entre la población, a pesar de que ese compromiso sólo se haya producido entre gente que carece de influencia, y a pesar del divorcio entre la conciencia de los ciudadanos y la voluntad de los gobiernos ${ }^{10}$.

Frente a la mayoría de los escritores contemporáneos, que muestran su preferencia por la gran ciudad, Delibes ha buscado "en el campo y en los hombres que lo pueblan la esencia de lo humano. Y cuando no era en el campo - en el mundo puramente rural - era en la pequeña capital de provincia asomada al llano o a la montaña" ". El escritor se ha aproximado así "a las pequeñas comunidades, dominado por la idea de que la megápolis uniformaba al hombre, que cada día resultaba más difícil hallar en la gran ciudad a un individuo, a un hombre diferenciado" 12 .

Delibes denuncia el fondo de hipocresía que subyace a una aparente tolerancia en el seno de las sociedades civilizadas:

Por este camino abocamos al sucedáneo, apelamos al civismo. Tratamos de construir una sociedad nueva, aséptica y sin roces; sin religión y sin guerras; una sociedad respetuosa y tolerante, donde el hombre deja de ser lobo para el hombre, aunque todo eso, antes que a un cálido derramamiento de corazón, se debe a una decisión cerebral demasiado fría para ser humana. La educación cívica engrasa así una convivencia que de otro modo, esfumada la solidaridad, resultaría impracticable. El civismo proporciona a las relaciones humanas una asepsia, pero no un calor ${ }^{13}$.

Un cierto sector de la crítica ha considerado que Delibes realiza un tratamiento rousseauniano, idf́lico, del ámbito rural. En varias ocasiones el novelista ha rebatido esta opinión, subrayando:

En rigor, antes que menosprecio de corte y alabanza de aldea, en mis libros hay un rechazo de un progreso que envenena la corte e incita a abandonar la aldea ${ }^{14}$.

En general, los personajes de Delibes son exponentes de lo que Gonzalo Sobejano ha llamado "inspiración compasiva", esto es, el resultado de una toma de postura autorial por los seres humillados y ofendidos, por las víctimas de un desarrollo tecnológico implacable.

Tal condición vincula a personajes tan aparentemente diversos como Eloy, el jubilado de La boja roja o su criada, la Desi; Mario, de Cinco horas; Jacinto Sanjosé, de Parábola del náufrago; Gervasio, de Madera de héroe, 
Daniel, de El camino; Pacífico, de Las guerras de nuestros antepasados, Azarías, de Los santos inocentes, etc.

Como ha expuesto C. A. de los Ríos, el autor "denuncia la perversión de las relaciones humanas en el sistema competitivo, la soledad de la vida urbana, los espejismos de la civilización, la degradación del hombre en los sistemas de poder personal, la devastación de la capacidad crítica de los ciudadanos por los mass media más poderosos" 15 . Es innegable que sus obras nacen de una profunda y actual conciencia dramática, de un sentido universal de la tragedia que emana de "las fuerzas que sobrepasan al hombre y contra las cuales se estrella su ser psíquico-existencial en su lucha por vencerlas" 16.

Este trasfondo moral que algunos han reprochado a la novelística delibeana, esa insistencia en la novela de tesis, no ha perjudicado en modo alguno a su difusión. Si hace algunos años Delibes era tildado de ruralista o de reaccionario, ahora su intención ética, por el contrario, lo sitúa en una perspectiva radicalmente actual. Gudrun Wogatzke, una especialista alemana en la obra de Delibes, considera acertadamente que "la preocupación por el campo y el medio ambiente, junto con cierto escepticismo en cuanto al progreso, hoy día nos parece una actitud más bien 'moderna', ecológica o liberal de izquierdas, antes que regresiva o reaccionaria" 17.

Delibes ha sido, en efecto, un ecologista "de primera hora" 18 ; lo fue mucho antes de que tal neologismo se acuñase. No es extraño que actualmente profesores de esa asignatura en las universidades españolas recomienden a sus alumnos la lectura de las novelas delibeanas - sobre todo Las ratas, Las guerras de nuestros antepasados, El disputado voto del señor Cayo y Los santos inocentes - como manuales de ecología rural. Y es que tales obras evidencian un profundo conocimiento del entorno natural, derivado de un contacto directo con la cultura campesina y de una experiencia íntima de vinculación a ese medio. El lenguaje de Delibes revela, en este sentido, una excepcional precisión en los términos, que no procede en ningún caso de un alarde estético, sino de una verdadera capacidad de distinción semántica.

La defensa del medio natural, expresada implícita o explícitamente en la obra de Delibes, va vinculada de manera muy estrecha, pues, a su convicción del camino errado que ha seguido el progreso a nivel mundial. Paulatinamente, la denuncia delibeana a tal estado de cosas se ha ido haciendo, según sus propias palabras, más acre y radical.

Su crítica, no obstante, no carece de un plantemiento paralelo de soluciones, a través de las cuales se adhiere a las propuestas elaboradas por el Club de Roma: frenar el desarrollo y organizar la vida comunitaria sobre bases dife- 
rentes a las que hasta abora han prevalecido, puesto que, de no hacerlo así, se consumará el suicidio colectivo en un plazo relativamente breve. Son las mismas tesis a las que recientemente han llegado organismos como la Comisión para el Medio Ambiente y el Desarrollo de Naciones Unidas y en cuya realización, sin embargo, ningún gobierno parece estar dispuesto realmente a colaborar.

En el mundo intelectual, a pesar de todo, parece que la reivindicación de una cultura rural empieza a tomar forma. Junto a Delibes, en España, aparecen nuevos narradores como los leoneses Luis Mateo Díez y Julio Llamazares o el gallego Manuel Rivas, que por el momento parecen ser los únicos concienciados de la necesidad de un cambio en la organización social. En la literatura europea, propone una salida por esta vía campesina el inglés John Berger, que en su trilogía Into their labors refleja el paso de la sociedad rural a la urbana con la consiguiente desaparición de la cultura rural en Europa Central. Por su parte, el alemán Günter Grass denuncia los tremendos resultados ecológicos de un desarrollo mal orientado en su libro Madera muerta.

\section{LA PRESENCIA DE DELIBES EN ALEMANIA.}

No resulta extraño, así las cosas, que Delibes, pese a ser considerado ya un clásico de la literatura espaniola del siglo XX en todos los países, goce de un particular prestigio en una sociedad tan desarrollada como la alemana.

El profesor Neuschäfer, en su conferencia en el curso que la Universidad Complutense dedicó al novelista en julio de 1991, aseguraba que Delibes es "de todos los autores españoles contemporáneos disponibles en Alemania [...], y con distancia, el más apreciado. En esta apreciación entra en juego también su rechazo de la sociedad de consumo. Precisamente porque Alemania es quizás el país económicamente más 'desarrollado' de Europa, se tiene ahí, sobre todo entre los intelectuales, una especial sensibilidad para los problemas de un desarrollo sin límites" ${ }^{19}$.

La recepción de Delibes en Alemania ha conocido dos momentos bien delimitados ${ }^{20}$. Puede decirse que hasta bien entrada la década de los ochenta, la literatura española de posguerra habla sido, en general, poco conocida fuera de las áreas universitarias especializadas. Sólo habían sido publicados libros de Cela, Luis Goytisolo, Fernández Santos, y alguno de Delibes, siempre en tiradas muy limitadas. El propio Delibes había visto traducidas tres de sus obras (Diario de un cazador, El camino y La hoja roja) en una editorial de Colonia, Bachem, que se especializó pronto en literatura religiosa, un tema 
muy desprestigiado en la Alemania del resurgimiento económico. De ahí que los libros de Delibes tuvieran entonces escaso éxito. Estas tres obras salieron a la luz, además, con títulos muy distintos a sus originales en español, sin conseguir llegar a un público joven abierto a nuevas propuestas intelectuales. El camino, por ejemplo, se tituló en aquella primera traducción Und zur Erinnerung Sommersprossen (algo así como "Y como recuerdo pecas de verano").

Posteriormente, ya en los setenta, se tradujeron otras obras. En la Alemania del Este, Cinco horas con Mario, publicada en el 76, fue considerada la despedida definitiva a la España franquista.

En cualquier caso, la primera recepción de Delibes en Alemania adoleció del desprestigio que, en la sociedad posnazi, sufrió todo producto nacido en un régimen semejante al que los alemanes trataban de olvidar. Y puesto que en la Alemania del nazismo no se produjo literariamente nada de calidad —si no fue en el exilio—, se dio por sentado, por lo demás, que en otros países con regímenes dictatoriales había de suceder lo mismo.

El enorme éxito de la novela hispanoamericana en Alemania eclipsó también nuestra literatura, que nunca obtuvo el reconocimiento que merecía.

Después de 1981, consolidada la democracia en España, se asiste a una nueva época en la recepción de Delibes y de la literatura española en general en Alemania. Paulatinamente aumenta el número de traducciones, y las obras se publican en tiradas cada vez más amplias. Después, sobre todo, de la feria del libro de Francfort en octubre de 1991, que tuvo a España como tema central, puede decirse que hoy día se está produciendo un auténtico boom de lo español, en consonancia ya con la conocida hispanofilia de ese país europeo.

Así pues, en la última década Delibes ha ocupado un puesto de excepción en la traducción de la literatura española al alemán. La editorial Piper -de Munich-, una de las más prestigiosas de Alemania, ha publicado Los santos inocentes, en 1987; La hoja roja, en 1988; en el 89, Cinco boras con Mario y, en el 90, Madera de héroe. La calidad de tales traducciones es bastante aceptable, si se tiene en cuenta "que es muy difícil, para no decir imposible, traducir adecuadamente un lenguaje tan castizo y tan cerca del ideolecto de sus personajes a una lengua tan abstracta como es el alemán" ${ }^{21}$.

El prestigio de Delibes se advierte no sólo ya en las publicaciones académicas sino también en las reseñas que las publicaciones de sus obras merecen en la prensa diaria y semanal, normalmente muy positivas, algo que no deja de sorprender en un medio normalmente muy crítico y tremendamen- 
te exigente.

A veces se han dado casos curiosos o divertidos de incomprensión de la obra de Delibes, característicos del desfase entre dos concepciones de la vida que siguen siendo distintas a pesar del acercamiento cultural y administrativo entre los países europeos de este final de siglo.

Así, por ejemplo, la familia numerosa en Madera de béroe se ha considerado - en un recurso a la literatura hispanoamericana que parece ser inevitable - un dato del "realismo mágico" de Delibes, algo lógico si se tienen en cuenta que en Alemania el primo hermano es ya alguien totalmente desconocido. También resultó problemática la interpretación de la ironía que subyace a la narración en esa novela, en una cultura que por lo general no admite ni comprende el discurso irónico.

De cualquier forma, prueba de este interés por Delibes son los innumerables trabajos que se realizan en todas las universidades alemanas a propósito de su obra. Especialistas como Hans Jörg Neuschäfer, Gudrun Wogatzke; estudiosos más que ocasionales como Sabine Pfleger, Inge Beisel, Karl Hermann Körner, Andreas Gelz, Karl Kohut, etc., dan la medida del prestigio de la obra delibeana en este país tan vinculado siempre a lo hispánico.

\section{DELIBES EN CHECOSLOVAQUIA.}

La resonancia y el interés de Delibes en el Este europeo ha sido quizás más intensa y constante, continua casi desde el inicio de su trayectoria narrativa. En la época del totalitarismo, y gracias precisamente a la solidez de su código moral, Delibes

logró situarse [...] en un ambiente dominado por una ideología adversa, aunque él nunca se había identificado con ella. Es que la mayoría de los lectores en aquel rincón de Europa perfectamente captaron no sólo los valores estéticos de sus novelas, sino también los valores éticos de éstas, tanto más ya que profundamente los anhelaban en su vida diaria ${ }^{22}$.

La obra de Delibes se introdujo en Checoslovaquia en 1972, con la traducción de Diario de un cazadory de Cinco horas con Mario, en un contexto dominado por las literaturas francesa y germánica y la obligada presencia de la literatura soviética.

Aunque ambos libros ofrecían escenarios muy lejanos a una Europa Central inmovilizada por el totalitarismo comunista, lo cierto es que las obras de Delibes lograron conectar y hacer llegar su mensaje a lugares tan heterogéneos como lo eran entonces los países europeos orientales ${ }^{23}$. Josef Forbelsky 
no ha dudado en explicar este fenómeno haciendo referencia a aquel elemento ético inherente a la prosa delibeana, una sustancia cuya función no se agotaba en satisfacer las exigencias de tipo estético, "sino que iba descubriendo la coherencia del carácter ético con la que aquel lector estaba sensibilizado por la constante aridez de su ambiente vital y social" ${ }^{24}$.

Detrás de las historias cinegéticas del conserje del instituto se vislumbraba el problema de la relación del hombre con la naturaleza. Tras los insistentes reproches de la viuda a su esposo difunto se constataba el profundo conflicto que ocasiona, en Cinco horas, la frustración vital de dos seres, el problema de la vida vivida como simulacro - cuestión que se trasladó a veces a una consideración del simulacro cotidiano al que estaba condenada por entonces la sociedad checoslovaca-. En definitiva, el lector de la Europa oriental descubría, más allá del microcosmos novelístico, la dimensión ética universal de la obra delibeana, una dimensión que parece descansar en la tradición milenaria del cristianismo europeo, de donde procede esta generalidad de planteamientos.

En relación con esa orientación cristiana de su narrativa, el propio autor comentó en su día:

Si yo pienso y siento -y supongo que escribo- en cristiano es porque no concibo otra manera de organizar la realidad que sobre la máxima 'amaos los unos a los otros' 25 .

El cristianismo de Delibes está enraizado, sin embargo, en una actitud claramente crítica y casi combativa: se siente obligado a reprobar los principios censurables de la religión, aunque tratando de reivindicarla intelectualmente. Delibes llama a "rechazar la religión recibida como un supuesto consuetudinario y social en el que el individuo se ha encontrado casi sin saberlo" ${ }^{26}$, entendiendo por el contrario la religión como un código perfecto de convivencia, favorecedor de la solidaridad entre los individuos, vinculado estrechamente a la realidad social de los individuos y comprometido en la lucha por la incorporación de los grupos marginados al estado del bienestar.

De acuerdo con ello, Delibes no ha reivindicado, ni siquiera en sus obras de la inmediata posguerra, una postura violenta que combata opresión con opresión, que responda a la violencia con violencia. De acuerdo con los que trataban de restituir la libertad, rechazando la instrumentalización por manos del poder estatal, ha seguido sin embargo un camino pacífico, fundamentado en los valores universales del cristianismo, la cultura y la ética europeas.

Es en ello, en definitiva, donde sin duda radica la extraordiaria aceptación de Delibes en la Europa del este, dominada durante años por regímenes 
totalitarios: en su obra "se transparentaban principios éticos que no tenían un carácter meramente táctico o instrumental, sino que se hallaban fundamentados sobre una base realmente profunda" ${ }^{27}$.

La obra que más claramente refleja la postura ética de Delibes respecto a la situación del Este europeo es su libro La primavera de Praga, escrito con motivo de la visita que realizó el escritor a Checoslovaquia en la histórica primavera de 1968, invitado por las Universidades de Praga y Brno. Delibes hizo el recorrido en coche, acompañado por su esposa Angeles. Las conclusiones del viaje se publicaron en forma de capítulos sueltos en la revista Triunfo, siendo recopilados después en forma de libro por Alianza Editorial.

En ese libro Delibes pretendía dejar constancia de la pacífica evolución política hacia un socialismo humanista y democrático que tuvo lugar durante su estancia en ese país. En el momento de su publicación, sin embargo, el proceso que Delibes reseñaba había sido ya frustrado por la intervención militar soviética, de modo que, en cierto aspecto, el libro nació muerto en su función testimonial.

Delibes no pudo evitar solidarizarse con el espíritu libertador que animaba a la sociedad checa durante esa primavera, aunque ya entonces previera el destino casi inevitable de aquel proceso. Continuamente presiente la intervención militar, ya casi fraguada en vísperas de su retorno a España: la primera dificultad de los checos — indicaba Delibes- "estriba en vencer el recelo de los rusos - que a mi regreso se han puesto a hacer 'maniobras' en la misma línea fronteriza checo-polaca, evidentemente con una finalidad disuasoria" ${ }^{28}$. Los países del Pacto de Varsovia, efectivamente, llegarian a intervenir con las armas para impedir la implantación del nuevo modelo de socialismo que los checos promovían.

El conjunto de la sociedad checoslovaca, capitaneada por intelectuales y estudiantes, se unía entonces en un esfuerzo por liberarse del régimen al que habían estado sujetos durante veinte años. Delibes se hizo eco de esa agitación, lo que dio un carácter marcadamente político —aunque inusual en su producción- a su crónica viajera. "A mi" - ha dicho Delibes- "me atrae preferentemente el aspecto humano del país que visito. Antepongo la calle a un museo. Únicamente en mi visita a Praga [...] no pude sustraerme a la tentación política. La política estaba en la calle, en todas partes, era el hombre" ${ }^{29}$.

Delibes emprende su análisis de la sociedad checa desde la óptica del hombre de la calle, sin pretensiones de analista político:

conocidas son -argumenta Delibes- mi inexperiencia politica y mi escasa 
formación sociológica y económica para afrontar un problema de tanta enjundia como éste. Pero los hombres de la calle no debemos retraernos de exponer nuestras observaciones ante otros hombres de la calle. En definitiva, el hombre de la calle es el beneficiario o la victima de estos vaivenes políticos $y$, por otro lado, es este diálogo entre aficionados, me parece, la única manera, por el momento, de que el susodicho hombre de la calle pueda comprender la importancia de ser hombre - aunque sea de la calle-y la trascendencia de su destino ${ }^{30}$.

La intuición y capacidad de síntesis de Delibes, junto al estilo coloquial y directo que adopta al exponer su experiencia, permiten al autor abordar un problema político e histórico de gran trascendencia con una enorme sencillez, precisión y eficacia.

En la reflexión sobre el fenómeno de los países comunistas, el escritor admite el concepto de revolución como móvil trascendental y factor positivo en el proceso histórico:

Las revoluciones desde el origen del hombre han pretendido un fin humano: hacer más vividero este mundo para un mayor número de personas cada vez [...]. Y si la revolución francesa dio acceso al poder y a la sociedad, a intelectuales y burgueses, la revolución rusa se lo dará al proletariado. Esto, creo yo, no hay quien lo mueva. Ahora bien, hay que confiar en que el terror, la tortura y el dogmatismo hayan sido ya digeridos (p. 24).

Ello no quiere decir, sin embargo, que Delibes aceptara las consecuencias derivadas de los principios de la filosofía marxista. El autor sólo admite el hecho de una transformación revolucionaria, la "redención popular", y ésta sólo como una metanoia colectiva", realizada en función de la deseada emancipación del individuo. Una transformación basada en la promesa salvífica del cristianismo: "un socialismo en libertad [...] es una forma de conviviencia que ya Cristo nos enseñó hace dos mil años y que [...] día a día nos recuerdan Juan XXIII y Pablo VI, aunque los cristianos, la mayor parte polarizados en la burguesía, reinventemos el cristianismo y desfiguremos las encíclicas a capricho por la cuenta que nos tiene" (p. 25).

Delibes rechaza cualquier fórmula de coacción individual, de ahí que rechace las dictaduras de cualquier signo: "Salía de una sociedad que no me gustaba para entrar en otra que me desagradaba no menos" (p. 11). Esta afirmación caracterizaba su dilema: "la situación de un ciudadano que se movía entre dos esferas que carecían de la indispensable libertad, siendo esta condición esencial para cada acto que en el orden de la praxis humana pudiera reconstruir el verdadero estatuto de la persona humana" ${ }^{32}$.

El proceso de la primavera de Praga preludiaba, por ello, la mayor esperanza social para Delibes, puesto que prometía al hombre una base sólida de autorrealización en la libertad, la cual unla a las conquistas progresivas de la 
sociedad hallazgos tan fundamentales para la dignidad humana como la educación igualitaria para todos los miembros de la población, la reforma agraria, la eliminación de los grupos de presión y de las acentuadas desigualdades en lo económico, la garantía de la seguridad, etc. (p. 23-24), esto es, lo que para Delibes es "la fórmula de convivencia del mundo futuro" (26).

El autor no ignoraba el fracaso económico propiciado por la aplicación de los principios marxistas. No admitía, sin embargo, la alternativa de la economía libre: "aquello de que ningún hombre sea explotado por otro hombre es la coronación de un proceso humanístico que viene de muy atrás, pero hay que estudiar la manera, asimismo, de que ningún hombre sea explotado por el Estado, obra, asimismo, de los hombres" (65). Para él, se hacía necesaria la búsqueda de soluciones intermedias.

Hoy día, la realidad de los antiguos países comunistas ha hecho evidente la conclusión delibeana acerca del fracaso de los principios marxistas. No hay lugar, sin embargo, para esa solución intermedia, porque la economía de mercado y, con ella, el utilitarismo y el consumismo paralelo se imponen en la práctica.

Otros acontecimientos revelan, en la actualidad, la certeza de los planteamientos de Delibes. En el prólogo a La primavera de Praga, redactado tras la intervención soviética, concluía el escritor: "Pese a todo, sigo creyendo en la posibilidad de hacer compatibles la justicia y la libertad y no dudo de que, a la larga, el paso dado por Rusia - torpe y brutal- acabará volviéndose contra ella" (8). El drama que actualmente se desarrolla en territorio soviético, las revueltas sociales, las convulsiones económicas que sacuden la vida diaria del antiguo imperio, dan la medida del acierto de Delibes en aquel presagio.

En ese prólogo Delibes manifestaba también una esperanza renovada: "Otros hombres - ital vez los mismos? - recogerán la antorcha. No olvidemos que si la vida humana es efímera, la Historia es perdurable" (8). En efecto, muchos de aquellos hombres que protagonizaron el intento democrático en el 68 - Havel, Dubcek, Hájek-, hoy han recogido la antorcha, protagonizando el proceso de cambio al que actualmente se asiste en ambas repúblicas checoslovacas, pacíficamente independizadas.

\section{EUROPA: PARADA Y FONDA Y DOS VIAJES EN AUTOMOVIL. OTRA VISION DE EUROPA.}

Además de La primavera de Praga, otros dos libros acogen la reflexión delibeana sobre la situación social de la Europa de nuestro siglo: Europa, 


\section{parada y fonda y Dos viajes en automóvil}

El primero, publicado por primera vez en 1963, es la segunda crónica viajera de Delibes, después de Por esos mundos (1961). En él recoge el autor impresiones de varias ciudades portuguesas, francesas e italianas. Esboza asI una lúcida interpretación sobre el estado cultural del occidente europeo de fin de siglo, si bien el autor no pretendía profundizar en aspectos políticos ni albergaba, en su elaboración, intereses filosóficos.

Con su modestia característica, el propio Delibes consideraba su libro un pequeño volumen, imparcial y casi frívolo, de impresiones. Pero de simples impresiones humanas, recogidas en el camino. Es evidente que el cambio de posición de Europa, la pérdida de su primacía material, facilita un tema de enorme interés y notable sugestión. Pero para quien conozca las pobres dotes del cronista no resulta menos evidente que abordar tamaño propósito escapa a sus posibilidades. Harían falta para ello mucho tiempo de observación, muchos contactos, innumerables consultas, una inteligencia aguda y muy hondas reflexiones, y el cronista [...] ni tiene tiempo, ni ha establecido contactos, ni ha consultado, ni es inteligente, ni apenas ha dedicado al garrapatear estas líneas algunos minutos a la reflexión ${ }^{33}$.

En sus viajes, Delibes otorga una singular importancia al valor de la "primera impresión": "En estos negocios de los viajes - dice en el prólogo a Por esos mundos- nada como la primera impresión; el destello inicial que viola la conciencia virgen es lo que vale". El autor sabe, sin embargo, conjugar esta primera impresión con "una segunda mirada, una mirada reflexiva, profunda, indagadora, que requiere tiempo para reparar en las cosas" ${ }^{34}$.

La unión de la sorpresa con la voluntad de superar lo anecdótico, lo transitorio o lo impersonal, favorece en el autor una asombrosa capacidad de captación del entorno al que accede, y le permite extraer conclusiones que, "sin pretender ser categóricas, resultan de una singular lucidez y verismo sobre un país y sobre su gente" ${ }^{35}$.

Ocurre, no obstante, que la realidad social que Delibes reseñaba hace ya treinta años ha cambiado sustancialmente con el paso del tiempo. Los libros de viajes son siempre circunstanciales, y, según esto, Delibes no dejaba de reconocer la eventualidad y la caducidad de sus impresiones: "No se me oculta - dice en alguna ocasión - que todo ello pudo ser circunstancial. Mas el cronista escribe desde su circunstancia y no por egoista deja de ser cierto aquello de que cada cual habla de la feria conforme le fue en ella" (Europa: parada y fonda, pp. 85-86).

En la reedición de Europa: parada y fonda (1981), Delibes insiste, sin embargo, en la perdurabilidad de los contenidos expuestos en ella:

$\mathrm{Al}$ releer estas páginas, escritas a vuela pluma hace veinticinco ańos, con objeto de comprobar si en nuestros días son o no de recibo, llego a la conclusión 
de que sí, puesto que en ellas hay cosas que no mudan, como Venecia o el carácter alemán, y otras, puramente circunstanciales, referidas a la Europa de la posguerra, aquella Europa de los 50 que tímidamente iniciaba su desarrollo - la Alemania del "milagro", la Italia de la "Vespa" o el París del existencialismo- que imprimen a estas crónicas viajeras un entranable aire "camp", un agridulce sabor nostálgico que, vistas desde la crisis actual, confieren al libro, ya que no otro valor, ese indefinible encanto, esa inefable emoción retrospectiva que nos asalta inevitablemente al ojear un viejo álbum de fotografias.

El libro Dos viajes en automóvil. Suecia y Países Bajos delata, por su parte, una visión muy actual del norte de Europa. Publicado en 1982, mantiene hoy día, sin lugar a dudas, su vigencia como documento histórico contemporáneo de la sociedad nórdica.

En todo caso, las crónicas viajeras de Delibes perduran porque cumplen el objetivo, pretendido por el autor, de "dar testimonio de vida". Ya en Por esos mundos apuntaba el escritor: "en realidad, el mundo es un gigantesco puzzle y uno, a medida que viaja, va encontrando los fragmentos que precisa para componer un mapa humano coordinado y armonioso".

Delibes se cuida muy bien de convertir sus observaciones en afirmaciones categóricas; excluye cualquier pretensión concluyente o dogmática acerca del carácter, las costumbres o las actitudes de las ciudades que visita. Ello no impide que sus conclusiones sorprendan, en la mayoría de los casos, por su precisión, su agudeza y su marcado carácter poético.

Veamos algunos ejemplos: "Venecia es, en suma, una posición tenaz del romanticismo en pleno siglo XX" (Europa: parada y fonda, p. 71); "Nápoles, antes que en la geografía, está en sus canciones [...]. Cuando los violines enmudecen, la impresión es exactamente la misma que si se nublase el sol" (95); "En Nápoles se ha sustituido el calor de hogar por el calor de barrio" (98); "Lo primero que sorprende al viajero a su entrada a Portugal es la inclinación de este pueblo hacia el adorno [...]. Italia es un país de artistas, mientras Portugal es un país de tímidos" (115); "El suizo ha desterrado los desniveles de sus caminos y de su sociedad. [...] La cara, entiendo yo, va dejando de ser el espejo del alma para pasar a ser el espejo de la economía. Es dificil hallar en un rostro suizo una expresión aviesa, hostil o simplemente ceñuda" (178).

No resulta extraño que Delibes otorgue una importancia decisiva al medio natural como factor determinante de la personalidad y el carácter de un pueblo. Al describir la naturaleza sueca, por ejemplo, no duda en afirmar: "El hombre que dispone de un árbol bajo el que cobijarse rara vez pierde los nervios. Y Suecia es un país forestal, un país literalmente de madera y sus 
pobladores adoptan ante la vida una cierta actitud vegetal, dicho en el mejor sentido de la expresión; esto es, crecen y se desarrollan sin apresuramientos, no dando un paso antes de afianzar el anterior" (Dos viajes en automóvil, p. 14).

Delibes no oculta su atracción por los países nórdicos, ejemplo, para él, del equilibrio entre el progreso y la defensa del medio natural. De este modo se expresa en el libro Dos viajes en automóvil:

A un paso del siglo XXI es alentador encontrar en la vieja Europa una reserva de Naturaleza natural como la sueca. Ellos son conscientes de ello; saben que esto no se da apenas por el mundo y la guardan, la preservan. Porque a esta riqueza natural insólita, el sueco responde con una sensibilidad por el medio ambiente también insólita en un siglo de practicismo, contaminación y despilfarro, donde el futuro apenas cuenta (16).

Ello no impide que el autor acuse también la frialdad que, en estos países, caracteriza la convivencia cotidiana:

Lo sorprendente del caso es que esta actitud de defensa gregaria, de grupo, este espíritu asociativo, no tenga una correspondencia en la vida normal, en la vida de todos los días, donde el sueco se muestra individualista y poco comunicativo, lo que prueba que su propensión a la asociación [...] es más cerebral que cordial, más calculada que afectiva. También faltan la luz y el calor aquil (25-26).

Delibes encontró en Suecia su fórmula ideal de organización sociopolítica, la realización del proyecto que vio frustrado en Checoslovaquia:

Los suecos, a mi juicio, han encontrado un orden de convivencia, después de casi medio siglo de gobierno socialdemócrata, que es el que menos mal ha resuelto hasta el momento el dilema libertad-justicia [...]. No creo que los suecos hayan divagado mucho sobre si su socialismo es marxista o no lo es; simplemente han aplicado unas normas que tienden a la nivelación y a la justicia social (35).

Aunque Delibes se muestra partidario de la movilización popular como motor de los cambios sociales, en alguna ocasión no ha podido evitar su desconcierto y su repulsa ante unas revueltas juveniles que, bajo la consigna de una falsa libertad, manipulan a sectores comúnmente pacíficos o apáticos inculcándoles su agresividad y su violencia. En su visita a Amsterdam, por ejemplo, el autor constata la rebeldía de jóvenes que se alzan contra una dudosa represión.

En una palabra - dice Delibes- la organización actual de la sociedad capitalista, y no digamos, de la socialista, no les va (y no me choca), es decir, su inconformismo no deja de estar justificado; el fallo radica en la nebulosidad de sus objetivos, en que saben con certeza lo que no quieren, pero carecen de unas ideas concretas sobre sus aspiraciones, sobre lo que quieren (Dos viajes 
en automóvil, 135-136).

En definitiva, la proyección de Delibes en Europa y, al mismo tiempo, el análisis riguroso que el propio escritor ha realizado de ese medio, responden a una particular visión de la existencia, a un planteamiento vital consecuente con las necesidades del hombre contemporáneo. La obra de Delibes revela un profundo compromiso con su tiempo, una acentuada insatisfacción por el rumbo equivocado que, a nivel mundial, sigue la civilización en nuestros días.

Con una literatura centrada en el hombre, Delibes ha defendido una postura crítica a lo largo de toda su trayectoria, sin renunciar a la convicción en el poder de la literatura como arma social. De ninguna manera la orientación ética en el ámbito artístico ha perdido ahora su sentido. Por el contrario, es precisamente en ello donde radica la universalidad de este escritor vallisoletano, que es, hoy por hoy, una de las personalidades literarias más admiradas dentro y fuera de nuestro país.

\section{NOTAS}

1 Miguel Delibes, "Prólogo" a La primavera de Praga, B., Destino, 1991 [Alianza Editorial, 1968], p. 15.

2 Pegar la bebra, ed. cit., pp. 103-202.

3 Ramón Garcia Domínguez, M.D.: un bombre, un paisaje, una pasión, B., Destino, 1985, p. 60.

4 Cfr. Rafael Conte, "Prólogo" a Cinco boras con Mario, B., Círculo de Lectores, 1983, p. IV.

5 V. Gladys Crescioni Neggers, "Cinco horas con M.D.", La Estafeta Literaria, núm. 565, 1 de junio de 1975, p. 8.

6 V. M.D., "Novela divertida y novela interesante", en La censura de prensa en los afios 40 (y otros ensayos), Valladolid, Ambito, 1985, p. 51.

7 V. Encarnación Garcla Dini, "Ideario de M.D.", Miscellanea di Studii Ispanici, núm. 16, 1968, pp. 289-330.

8 El mundo en la agonia, B., Clirculo de Lectores, 1988, p. 9.

9 V. César Alonso de los Rios, "Conversaciones en el invierno del 92", en Conversaciones con M.D., B., Destino, 1993, p. 165.

10 Cfr. id., pp. 167-168.

11 Miguel Delibes, "Un hombre de aire libre", en Pegar la hebra, B., Destino, 1990, p. 199.

12 Id.

13 Miguel Delibes, "Prólogo" a su Obra Completa, B., Destino, 1968, pp. 10-11.

14 El mundo en la agonia, ed. cit., pp. 98-99.

15 César Alonso de los Rlos, Conversaciones con M.D., M., Magisterio Espafíol, 1971, p. 17. 
Mario Naudon de la Sotta, Apreciación teatrah Santiago de Chile, Ed. del Paclfico, 1956, p.41

7 Gudrun Wogatzke-Luckow, "La evolución de las posiciones ideológicas en el repertorio de personajes en la obra narrativa de M.D. (1947-1987)", en CUEVAS GARClA, Cristóbal (dir.), M.D. El escritor, la obra y el lector, ed. cit., p. 192.

18 Asi lo expresa Fernando Parra en su conferencia "D. al aire libre: un ecologista de primera hora", en VV.AA., M.D.: Premio Letras Espafiolas 1991, M., Ministerio de Cultura, 1993.

19 Hans-Jörg Neuschäfer, "D. en Alemania", en JIMÉNEZ LOZANO, José (dir.), El autor y su obra: M.D., M., Actas de El Escorial, 1993, p. 121.

20 V. sobre todo id., pp. 119-122.

21 H.J. Neuschäfer, id., p. 121.

22 Josef Forberlsky, "Delibes y su visión del Este europeo", en JIMÉNEZ LOZANO, J., op. cit., p. 132.

23 Cfr. Josef Forbelsky, "El fondo ético de la obra de M.D.", en VV.AA., M.D. Premio Letras Españolas 1991, ed. cit., p. 116. Id.

Próloga a su Obra Completa III, ed. cit., p. 11.

28 La primavera de Praga, pp. 117-118.

29 V. Ramón García Domínguez, "M.D., viajero", prólogo a Europa: parada y fonda, B., Plaza y Janés, 1981, p.15.

30 M.D., "Prólogo" a La primavera de Praga, pp. 15-16.

31 Cfr. Forbelsky, "El fondo ético de la obra de M.D.", loc. cit., p. 120.

32 Id.

33 Miguel Delibes, Europa, parada y fonda, B., Plaza y Janés, $1981^{2}$, p. 45.

34 V. Ramón Garcla Domínguez, "M.D., viajero", prólogo a id., p. 12.

35 Ramón García, "El mundo y yo. (Libros de viajes de M.D.)", en JIMÉNEZ LOZANO, José, El autor y su obra: M.D., ed. cit., p. 171. 